\title{
HUBUNGAN TINGKAT PENGETAHUAN IBU DENGAN PERKEMBANGAN MOTORIK KASAR ANAK USIA ( 3 - 5 TH )
}

\author{
Nur Hasanah* \\ Muhsinin Nisa Ansori** \\ *Dosen Program Studi Diploma III Kebidanan Universitas Islam Lamongan \\ **Mahasiswa Program Studi Diploma III Kebidanan Universitas Islam Lamongan
}

\begin{abstract}
ABSTRAK
Anak bukan orang dewasa tetapi individu yang unik dan mempunyai kebutuhan khusus. Perkembangan optimal di mulai usia 0-5 tahun, di negara berkembang masih tingginya keterlambatan perkembangan motorik kasar usia 3-5 tahun (49\%) masih terdapat keterlambatan 8,83\%. sehingga ibu harus memperhatikan perkembangan anaknya sesuai dengan umurnya. Jenis penelitian observasional pendekatan secara crossectonal, instrumen menggunakan DDST, populasi sebanyak $38 \mathrm{ibu}$, sampel $34 \mathrm{di}$ ambil secara sample randem sampling, uji korelasi spearmen dengan tingkat kemaknaan $\alpha=0,05$.

Hasil penelitian bahwa dari 34 responden didapatkan $(58,83 \%)$ sebagian besar ibu memiliki pengetahuan baik, $(88,23 \%)$ perkembangan motorik kasar terhambat. Setelah di lakukan uji korelasi spearmen ternyata hasilnya $0,001<$ 0,05 maka $\mathrm{H}_{0}$ di tolak. simpulan ada hubungan tingkat pengetahuan ibu dengan perkembangan motorik kasar anak usia 3-5 tahun. Maka pengetahuan ibu tentang perkembangan motorik kasar di tingkatkan sehingga perkembangan anak tidak terhambat dan akan sesuai tahap perkembangannya hal ini sama dengan pendapat.
\end{abstract}

Kata Kunci : Tingkat Pengetahuan Ibu, Perkembangan Motorik Kasar

\section{PENDAHULUAN}

Pertumbuhan

perkembangan merupakan aspek yang menjelaskan mengenai proses pembentukan seseorang, baik secara fisik maupun psikososial. Namun sebagian orang tua belum memahami hal ini, terutama orang tua yang mempunyai tingkat pengetahuan dan sosial ekonomi yang sangat rendah. Mereka menganggap bahwa selama anak tidak sakit, berarti anak tidak mengalami masalah kesehatan termasuk pertumbuhan dan perkembangan anak tersebut. Sering juga para orang tua mempunyai pemahaman bahwa pertumbuhan dan perkembangan mempunyai pengertian yang sama (Nursalam, 2005).

Perkembangan motorik kasar pada anak dibawah umur lima tahun tercatat sebanyak 49\%, akibat pengetahuan ibu yang terjadi di negara berkembang. Kelambatan perkembangan motorik kasar sebanyak $50 \%$ di Asia, di Afrika sebanyak $30 \%$, dan $20 \%$ terjadi pada anak-anak di Amerika Latin (Wordpress, 2009).

Perkembangan anak melalui perkembangan fisik, kognitif, emosi, bahasa, motorik (kasar dan halus). Personal sosial, deteksi dini dan intervensi dini sangat membantu agar tumbuh kembang anak dapat 
berlangsung seoptimal mungkin. Peran orang tua dalam tumbuh kembang anak sangat besar ( Soetjiningsih, 1995).

Akibatnya, pada umur tertentu anak belum bisa melakukan tugas perkembangan yang sesuai dengan kelompok umurnya. Bahayanya penyebab terlambatnya perkembangan motorik, sebagian dapat dikendalikan dan sebagian lagi tidak. Kurangnya stimulasi terjadi terlambatnya motorik kasar yang disebabkan gangguan organis di otak yang berupa dispraxia adalah gangguan di pusat-pusat tertentu yang mengalami kesulitan meski sudah terlatih (Tedjasaputra, 2003)

Cara terbaik untuk mencegah kelambatan pertumbuhan dan perkembangan adanya masalah dan ibu harus mempunyai pengetahuan untuk memperhatikan pertumbuhan dan perkembangan anaknya misalnya dalam Faktor internal kecerdasan, pengaruh Hormonal, pengaruh emosi. Faktor lingkungan misalnya pada pra natal, lingkungan, nutrisi. Adapun pengetahuan pertumbuhan dan perkembangan harus selalu diperhatikan sama ibu untuk anaknya sehingga pertumbuhan dan perkembangan anak tidak terhambat dan tidak dengan sesuai umurnya ( Narendra, 2002 )

\section{TUJUAN PENELITIAN}

Menganalisis hubungan tingkat pengetahuan ibu dengan perkembangan motorik kasar anak usia (3-5 tahun).

\section{TINJAUAN PUSTAKA \\ Konsep Dasar Pengetahuan}

Pengetahuan merupakan hasil dari tahu, dan ini terjadi setelah orang melakukan penginderaan terhadap suatu objek tertentu.
Penginderaan terjadi melalui panca indera manusia, yakni indera penglihatan, pendengaran, penciuman, rasa, dan raba. Sebagian besar pengetahuan manusia diperoleh melalui mata dan telinga. Pengetahuan atau kognitif merupakan domain yang sangat penting dalam membentuk tindakan seseorang

\section{Tingkatan Pengetahuan}

$$
\text { Menurut Notoatmodjo }
$$

(2003) pengetahuan yang tercakup dalam domain kognitif mempunyai 6 tingkatan, yaitu

1. Tahu (know)

2. Memahami (comprehension)

3. Aplikasi (aplication)

4. Analisis (analysis)

5. Sintesis (synthesis)

6. Evaluasi (evaluation)

\section{Pengukuran Pengetahuan}

Pengukuran pengetahuan dapat dilakukan dengan wawancara atau angket yang menanyakan tentang isi materi yang ingin di ukur dari subjek penelitian atau responden.

Indikator yang dapat digunakan untuk mengetahui tingkat pengetahuan, dapat dikelompokkan menjadi (Notoatmodjo, 2003)

Pengetahuan tentang sakit

Pengetahuan tentang sakit dan penyakit yang meliputi :

1. Pengobatan, atau kemana mencari pengobatan.
a. Bagaimana
cara penularannya.
b. Bagaimana pencegahannya.
cara

1. Pengetahuan tentang cara pemeliharaan kesehatan dan cara hidup sehat. 
2. Pengetahuan tentang kesehatan lingkungan.

\section{Konsep Dasar Anak}

Anak adalah seseorang yang belum mencapai umur 21 tahun dan belum pernah kawin. Batasan umur ini di tetapkan oleh karena berdasarkan pertimbangan usaha kesejahteraan sosial, kematangan pribadi dan kemantangan mental seorang anak di capai pada umur 21 tahun.

\section{Prinsip-Prinsip Anak}

1. Anak adalah bukan miniatur orang dewasa tetapi merupakan sosok individu yang unik yang mempunyai kebutuhan khusus sesuai dengan tahapan perkembangan dan pertumbuhan.

2. Berdasarkan kepada pertumbuhan dan perkembangan anak sehingga permasalahan perawatan terhadap klien sesuai dengan tahapan perkembangan anak.

3. Asuhan kesehatan yang di berikan menggunakan pendekatan sistem.

\section{Konsep Dasar Perkembangan}

Perkembangan adalah bertambahnya kemampuan ( skill ) dalam struktur dan fungsi tubuh yang lebih kompleks dalam pola yang teratur sebagai dari proses pematangan.

\section{Penilaian Perkembangan}

Untuk menilai perkembangan anak pertama yang dapat di lakukan adalah dengan wawancara tentang faktor kemungkinan yang menyebabkan gangguan dalam perkembangan, kemungkinan melakukan tes skrining perkembangan anak dengan denver devolopmental screening test, tes IQ dan tes psikologi lainnya selain itu juga dapat di lakukan tes lainnya seperti evaluasi dalam lingkungan anak yaitu interaksi anak selama ini, evaluasi fungsi penglihatan, pendengaran, bicara, bahasa, serta melakukan pemeriksaan fisik lainnya seperti pemeriksaan neurologis, metabolik, dan lain - lain

Dalam tes skrining test ini banyak beberapa tes yang dapat di gunakan di antaranya tes intelegensi wechsler untuk anak prasekolah dan sekolah, skala perkembangan menurut gesell ( gesell infant scale), skala bayle ( bayley infant scale of development ), tes bentuk geometrik, tes motor visual bender gestalk, tes menggambar orang, tes perkembangan adaptasi sosial , DDST, diagnostik perkembangan fungsi munchen tahun pertama. Dalam cara penelitian tes perkembangan dalam hal yang akan di jelaskan adalah cara menurut denver ( DDST ) dan diagnostik perkembangan fungsi muncshen tahun pertama

\section{Konsep Dasar Denver Developmental Screening Test}

Denver II adalah revisi utama dari standardisasi ulang dari Denver Development Screening Test (DDST) dan Revisied Denver Developmental Screening Test (DDST-R). Adalah salah satu dari metode skrining terhadap kelainan perkembangan anak. Tes ini bukan tes diagnostik atau tes IQ. Waktu yang dibutuhkan 15-20 menit.

\section{Aspek Perkembangan yang Dinilai

Terdiri dari 125 tugas
perkembangan.

Tugas yang diperiksa setiap kali skrining hanya berkisar 25-30 tugas. Ada 4 sektor perkembangan yang dinilai: 
1. Personal Social (perilaku sosial)

Aspek yang berhubungan dengan kemampuan mandiri, bersosialisasi dan berinteraksi dengan lingkungannya.

2. Fine Motor Adaptive (gerakan motorik halus)

3. Language (bahasa)

4. Gross motor (gerakan motorik kasar)

Alat yang digunakan

1. Alat peraga: benang wol merah, kismis/ manik-manik, Peralatan makan, peralatan gosok gigi, kartu/ permainan ular tangga, pakaian, buku gambar/ kertas, pensil, kubus warna merahkuning-hijau-biru, kertas warna (tergantung usia kronologis anak saat diperiksa).

2. Lembar formulir DDST II

Buku petunjuk sebagai referensi yang menjelaskan cara-cara melakukan tes dan cara penilaiannya.

\section{Uprosedur DDST}

Prosedur DDST terdiri dari 2 tahap, yaitu:

1. Tahap pertama: secara periodik dilakukan pada semua anak yang berusia:
1) 3-6 bulan
2) $9-12$ bulan
3) 3-24 bln
4) 3 tahun
5) 4 tahun
6) 5 tahun

2. Tahap kedua: dilakukan pada mereka yang dicurigai adanya hambatan perkembangan pada tahap pertama. Kemudian dilanjutkan dengan evaluasi diagnostik yang lengkap.

\section{Cara Pengukuran Pemeriksaan DDST}

1. Tetapkan umur kronologis anak, tanyakan tanggal lahir anak yang akan diperiksa. Gunakan patokan 30 hari untuk satu bulan dan 12 bulan untuk satu tahun.

2. Jika dalam perhitungan umur kurang dari 15 hari dibulatkan ke bawah, jika sama dengan atau lebih dari 15 hari dibulatkan ke atas.

3. Tarik garis berdasarkan umur kronologis yang memotong garis horisontal tugas perkembangan pada formulir DDST.

4. Setelah itu dihitung pada masingmasing sektor, berapa yang $\mathrm{P}$ dan berapa yang $F$.

5. Berdasarkan pedoman, hasil tes diklasifikasikan dalam: Normal, suspek

Penilaian

$$
\text { Untuk menilai DDST }
$$

keseluruhan menurut (Heru Santoso: 2009) meliputi Jika Lulus (Passed = $\mathrm{P})$, gagal $($ Fail $=\mathrm{F})$, ataukah anak tidak mendapat kesempatan melakukan tugas (No Opportunity = NO).

\section{1) Normal / Sesuai \\ Interprestasi NORMAL di} berikan jika tidak ada skor " Terlambat " ( $0 \mathrm{~T})$ dan atau maksimal 1 " peringatan " ( $1 \mathrm{P})$. Jika hasil ini di dapat, lakukan pemeriksaan ulang pada kunjungan berikutnya.

2) Suspek / Meragukan

Interprestasi SUSPEK di berikan jika terdapat satu atau lebih skor " terlambat " ( 1 P) dan atau dua atau lebih " peringatan " ( $2 P$ ). Ingat,dalam hal ini, $T$ dan $P$ harus di sebabkan oleh kegagalan ( $G$ ), bukan oleh penolakan ( $M$ ). Jika hasil ini di dapat, lakukan uji ulang dalam 1-2 minggu mendatang untukmenghilangkan faktor- faktor 
sesaat, seperti rasa takut, sakit atau kelelahan.

3) Tidak dapat di uji / Penyimpangan Interprestasi TIDAK DAPAT DI UJI di berikan jika terdapat satu atau lebih "Peringatan " (2 P ). Ingat, dalam hal ini, $\mathrm{T}$ dan $\mathrm{P}$ harus di sebabkan oleh penolakan ( $M$ ), bukan oleh kegagalan ( G). Jika hasil ini di dapat, lakukan uji ulang dalam 1- 2 minggu mendatang.

Catatan : Jika hasil tes berulang kali menunjukan SUSPEK atau TIDAK DAPAT DI UJI, anak perlu menjalani sesi konsultasi dengan seorang ahli guna menentukan keadaan klinis anak berdasarkan

1. profil hasil tes ( item yang mendapat nilai " Peringatan " atau "Terlambat"

2. jumlah " Peringatan " dan "Terlambat "

3. tingkat perkembangan sebelumnya

4. perhatian klinis lainnya ( riwayat klinis, pemeriksaan kesehatan dll.)

5. sumber rujukan yang tersedia. ( Heru Santoso: 2009)

Meragukan dan tidak dapat dites.Menurut (Soetjiningsih, 1995).

\section{Konsep Dasar Pendidikan Anak Usia Dini}

Pendidikan anak usia dini (PAUD) adalah jenjang pendidikan sebelum jenjang pendidikan dasar yang merupakan suatu upaya pembinaan yang ditujukan bagi anak sejak lahir sampai dengan usia enam tahun yang dilakukan melalui pemberian rangsangan pendidikan untuk membantu pertumbuhan dan perkembangan jasmani dan rohani agar anak memiliki kesiapan dalam memasuki pendidikan lebih lanjut, yang diselenggarakan pada jalur formal, nonformal, dan informal.
Tujuan PAUD

1. Tujuan utama

Untuk membentuk anak Indonesia yang berkualitas, yaitu anak yang tumbuh dan berkembang sesuai dengan tingkat perkembangannya sehingga memiliki kesiapan yang optimal di dalam memasuki pendidikan dasar serta mengarungi kehidupan di masa dewasa.

2. Tujuan penyerta

Untuk membantu menyiapkan anak mencapai kesiapan belajar (akademik) di sekolah.

\section{$\underline{\text { Ruang Lingkup Pendidikan Anak }}$}

Usia Dini

1. Infant (0-1 tahun)

2. Toddler (2-3 tahun)

3. Preschool/ Kindergarten children (3-6 tahun)

4. Early Primary School (SD Kelas Awal) (6-8 tahun)

$\underline{\text { Bahan dan Perlengkapan Belajar }}$

1. Sederhana,

2. Konkrit

3. Sesuai dengan dunia kehidupan anak

4. Terkait dengan situasi pengalaman langsung

5. Atraktif dan berwarna

6. Mengundang rasa ingin tahu anak

7. Bermanfaat, dan

8. Terkait dengan aktivitas-aktivitas bermain anak. Belajar berbagai hal bagi anak. (Departemen Pendidikan Nasional, 2002)

$\underline{\text { Penilaian }}$

1. Hendaknya lebih ditekankan penggunaannya adalah yang bersifat autentik dan natural, yang lazim dikenal dengan penilaian portofolio 
2. Penilaian yang bersifat autentik memiliki beberapa karakteristik berikut:

1) Tidak disajikan dalam bentuk nilai yang disimbolkan dengan angka dan huruf;

2) Mendorong anak untuk mengevaluasi karyanya sendiri dan untuk menentukan pada bagian mana diperlukan adanya upaya peningkatan;

3) Kesalahan-kesalahan yang dipandang sebagai sesuatu yang wajar dan merupakan bagian yang diperlukan dari kegiatan belajar;

4) Terutama dilakukan melalui observasi dan pencatatan;

5) Kemajuan anak dilaporkan kepada orang tua dalam bentuk komentar-komentar yang bersifat naratif;

6) Kemajuan dilaporkan dengan membandingkan prestasi anak sekarang dengan yang pernah diperolehnya pada masa-masa lampau;

7) Orang tua diberi informasi secara umum tentang bagaimana keadaan anaknya bila dibanding dengan rata-rata penampilan anak pada umumnya;

8) Anak tidak "dipromosikan" dan tidak perlu dianggap mengalami "kegagalan";

9) Tinggal kelas dihindari karena alasan dampak psikologis yang negatif terhadap rasa harga diri anak

\section{HIPOTESIS}

Ada hubungan antara tingkat pengetahuan ibu dengan perkembangan motorik kasar anak usia (3 - 5 tahun).

\section{METODE PENELITIAN}

Jenis penelitian analitik observasional dengan cross sectional, populasi sebanyak $38 \mathrm{ibu}$ yang mempunyai anak usia $3-5$ tahun, Sampel 34 orang dengan cara Simple random sampling, analisa data digunakan adalah uji spearman.

\section{HASIL PENELITIAN}

Hasil penelitian bahwa seluruhnya 17 (100\%) responden berpengetahuan baik dengan perkembangan motorik kasar anak usia $3-5$ tahun sesuai tahap perkembangannya, dan tidak satupun $0 \quad(0 \%)$ responden berpengetahuan kurang dengan perkembangan motorik kasar anak usia $3-5$ tahun sesuai tahap perkembangannya.

Dari hasil statistik uji korelasi spearman $\left(r_{s}\right)$ didapatkan $\left(\mathrm{r}_{\mathrm{s}}\right)=$ 0,562 , nilai Sig 2 tailed $(p)=0,001$ dan dengan uji SPSS versi 16,0 dengan $\mathrm{p}:<0,05$, maka Ho ditolak dan H1 diterima yang berarti ada hubungan pengetahuan ibu dengan perkembangan motorik kasar anak usia 3 - 5 tahun.

\section{PEMBAHASAN}

\section{Pengetahuan Ibu}

Hasil pengetahuan ibu bahwa sebagian besar sebanyak 17 (50\%) responden berpengetahuan baik dengan perkembangan motorik kasar anak usia 3 - 5 tahun dan sebagian kecil sebanyak 3 ( 8,82\%) responden berpengetahuan kurang dengan perkembangan motorik kasar anak usia 3- 5 tahun.

$$
\text { Pada kenyataannya }
$$

pengetahuan sangat berpengaruh bagi ibu apalagi tentang perkembangan motorik kasar. Banyak ibu yang mengetahui apa dan bagaimana cara merawat anaknya tanpa memperhatikan keadaan anaknya. 


\section{Perkembangan Motorik Kasar Anak Usia 3 - 5 Tahun}

Hasil penelitian bahwa hampir seluruhnya $30 \quad(88,23 \%)$ responden sesuai tahap perkembangan dan sebagian kecil 1 ( 2,94\%) responden meragukan perkembangan motorik kasar anak usia 3 - 5 tahun.

Untuk menilai perkembangan anak pertama yang dapat dilakukan dengan wawancara kemudian melakukan tes skrining perkembangan anak dengan denver devolopmental screening test, tes IQ dan tes psikologi lainnya selain itu juga dapat dilakukan tes lainnya seperti evaluasi dalam lingkungan anak yaitu interaksi anak selama ini, evaluasi fungsi penglihatan, pendengaran, bicara, bahasa, serta melakukan pemeriksaan fisik lainnya seperti pemeriksaan neurologis, metabolik, dan lain - lain

\section{Hubungan Tingkat Pengetahuan} Ibu Dengan Perkembangan Motorik Kasar Anak Usia 3 - 5 Tahun

Berdasarkan penelitian bahwa seluruhnya $17 \quad(100 \%)$ responden berpengetahuan baik dengan perkembangan motorik kasar anak usia 3 - 5 tahun sesuai tahap perkembangannya, dan tidak satupun $0 \quad(0 \%)$ responden berpengetahuan kurang denagn perkembangan motorik kasar anak usia $3-5$ tahun sesuai tahap perkembangannya.

Pengetahuan ibu sangat berpengaruh pada perkembangan motorik kasar anak usia 3-5 tahun karena dalam masa ini sangat penting untuk perkembangan anak .

SIMPULAN DAN SARAN Simpulan

$\begin{array}{lcr}\text { Ada } & \text { hubungan } & \text { tingkat } \\ \text { pengetahuan } & \text { ibu } & \text { dengan } \\ \text { perkembangan } & \text { motorik kasar anak } \\ \text { usia 3-5 tahun. } & & \end{array}$

\section{Saran}

Petugas kesehatan agar memberikan penyuluhan tentang pentingnya perkembangan motorik kasar anak usia 3 - 5 tahun.

\section{DAFTAR PUSTAKA}

Admin, 2008. Ilmu kesehatan Anak , EGC. Jakarta

Arikunto Suharsimi. 2006. Prosedur Penelitian Suatu Pendekatan Praktek. Jakarta. Rineka Cipta.

Heru Santoso, 2009. Panduan DDST, EGC. Jakarta

Narendra. 2002. Ilmu Kesehatan Anak. EGC. Jakarta

Notoatmodjo, Soekidjo, 2003.Ilmu Kesehatan Masyarakat.

Cetakan 1. EGC: Jakarta

Nursalam, 2005. Konsep Dan Penerapan Metodologi Penelitian Ilmu Keperawatan. Salemba Medika. Jakarta

Soetjiningsih. 1995. Tumbuh Kembang Anak . EGC. Jakarta

Tedjasaputra, 2003. Asuhan Kesehatan Anak. Jakarta

Wordpress, 2009. www Pertumbuhan Dan Perkembangan Anak. 